\title{
Anti-melanogenic and Anti-oxidant Activities of an Ethanolic Extract of Kummerowia striata and its active compounds, p-coumaric acid and quercetin
}

Ju-Hyoung Park ${ }^{1,+}$, Jae Yeon Lee ${ }^{2,+}$, Young-Rak Cho², Eun-Kyung Ahn², Wonsik Jeong ${ }^{2}$, Hyoung Seok Shin ${ }^{3}$, Mi-Sun Kim³ ${ }^{3}$ Joa Sub Oh ${ }^{1, *}$

1 Department of Pharmacy, College of Pharmacy, Dankook University, 119 Dandae-ro, Cheonan, 330-714, Republic of Korea; 72160511@dankook.ac.kr

2 Bio-Center, Gyeonggi Institute of Science and Technology Promotion, 147 Gwanggyo-ro, Yeongtong-gu, Suwon-si, Gyeonggi-do, 443-270, Republic of Korea; jyeon@gbsa.or.kr; yrcho@gbsa.or.kr; aek@gbsa.or.kr; ws2009@gbsa.or.kr

3 HANSOLBIO Co., Ltd., Halla Sigmavalley 545, Dunchon-daero, Jungwon-gu, Seongnam-si, Gyeonggi-do, Republic of Korea; hansolbil@hansolbio.com; a592007@hansolbio.com

* Correspondence: jsoh@dankook.ac.kr; Tel.: +82-41-550-1435

\begin{abstract}
Kummerowia striata is a traditional medicine used for the therapy of inflammation-related diseases. Herein, we investigated the anti-melanogenic and antioxidant activities of an ethanolic extract of K. striata (EKS) using a number of in vitro and cell culture model systems. The antimelanogenic effect was assessed in B16F10 melanoma cells based on melanin synthesis and in vitro tyrosinase inhibitory activity and the anti-oxidant activity assays were performed using 2,2diphenyl-1-picrylhydrazyl (DPPH) and 2,2'-azino-bis (3-ethylbenzothiazoline-6-sulfonic acid) diammonium salt (ABTS); EKS exhibited strong anti-oxidant activities in both the assays. The expression of tyrosinase, tyrosinase-related protein 1, tyrosinase-related protein 2, and microphthalmia-associated transcription factor was decreased in a dose-dependent manner at mRNA and protein levels upon treatment with EKS. Notably, EKS did not affect the cell viability at all the EKS concentrations used in this study, indicating that EKS-mediated inhibition of melanin synthesis is not accompanied with cytotoxicity. Collectively, our findings demonstrate, for the first time, that EKS possesses anti-melanogenic and anti-oxidant activities, and suggest that further evaluation and development of EKS as a functional supplement or cosmetic might be useful for skin whitening and for reduction wrinkles.
\end{abstract}

Keywords: Kummerowia striata; anti-oxidant activity; melanin synthesis; p-coumaric acid; quercetin

\section{Introduction}

Understanding of the fundamental causes of human aging has received much attention in modern science. With increasing prosperity, people are more interested in preventing aging of the body as well as its manifestation in external bodily attributes. Skin ageing is the main external manifestation of aging and several studies on skin aging have played a major role in understanding human aging [1,2]. The aging of the skin can be divided into two types: chronologic aging, which is accompanied by the progressive deterioration of the structure and function of skin over time, and exogenous aging (photoaging), which is caused by changes in skin texture as a result of long-term exposure to sunlight [3,4]. Free radicals and reactive oxygen species are considered the most important factors in skin aging research. They are naturally produced in vivo, but are also generated upon exposure to sunlight and various chemicals. Free radicals and reactive oxygen species are 
generated by oxidative stress in skin cells and the substances generated during this process are involved in the production of melanin and formation of wrinkles.

Melanocytes play an important role in protecting the skin from radiation damage $[5,6]$. The biosynthesis of melanin in melanocytes is mediated by the enzyme, tyrosinase, which regulates the formation of L-3,-4-dihydroxyphenylalanine (L-DOPA) by the hydrolysis of tyrosine, and the formation of DOPA quinone by the oxidation of DOPA [7,8]. Micro-ocular tissue-related transcription factor (MITF) is a key transcription factor that regulates the transcription of melanogenic enzymes, namely Tyrosinase, TRP-1, and TRP-2 [9,10]. It plays an important role in the melanin synthesis pathway [11,12].

Kummerowia striata (Thunb. ex Murray) Schindl is an annual plant, indigenous to eastern Asia, including Korea, China, and Japan. It has long been used as a traditional medicinal herb for inflammation-related therapies. The aim of this study was to analyze the anti-melanogenic and antioxidant activities of the ethanolic extract of $K$. striata (hereafter, referred to as EKS) and two compounds. The antioxidant activities were determined by assessing the free radical scavenging activities using ABTS and DPPH assays and the anti-tyrosinase activity was assessed using the tyrosinase inhibition assay. Our results demonstrate that EKS and the two compounds are very promising candidates for use in cosmetic products for whitening of skin and for reducing wrinkles.

\section{Results}

\subsection{Anti-melanogenic Effects of EKS}

Because tyrosinase is a key enzyme catalyzing the rate-limiting step in melanin biosynthesis, we performed a tyrosinase assay to determined the anti-melanogenic activity of EKS. For this, we used a mushroom tyrosinase and L-tyrosine, as a substrate. As can be seem from Figure 1A, EKS exerted a significant inhibitory effect on tyrosinase activity in a dose-dependent manner, suggesting that EKS inhibited the activity of mushroom tyrosinase similar to arbutin, which was used as a positive control. To determine the consequence of the inhibition of tyrosinase activity on melanin production, we quantified the melanin content in EKS-treated B16F10 melanoma cells. As is evident from Figure 1B, EKS treatment caused a decrease in the melanin content of melanoma cells in a dose-dependent manner, indicating that this decrease might be due to the inhibition of tyrosinase activity. Moreover, cell viability assay revealed that EKS had no significant cytotoxic effect on B16F10 cells at the concentrations used. These findings clearly demonstrtate that EKS exerts anti-melanogenic effects through inhibition of the tyrosinase activity, and consequently of melanin synthesis, in B16F10 melanoma cells without inducing cytotoxicity. 
A

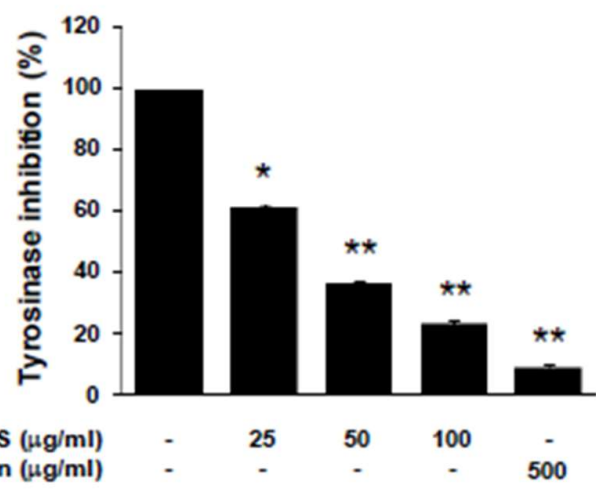

B

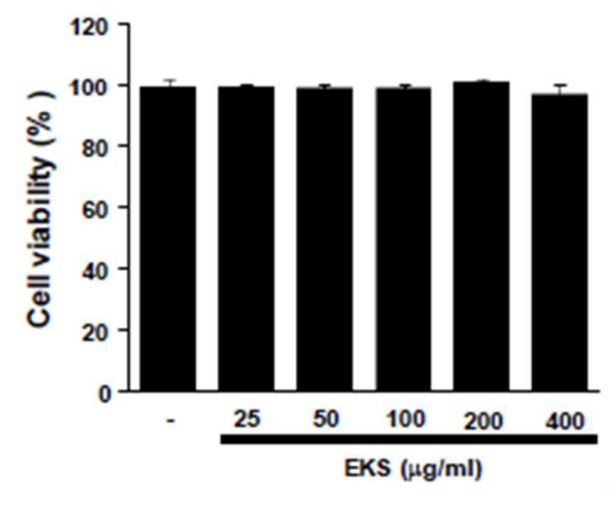

C

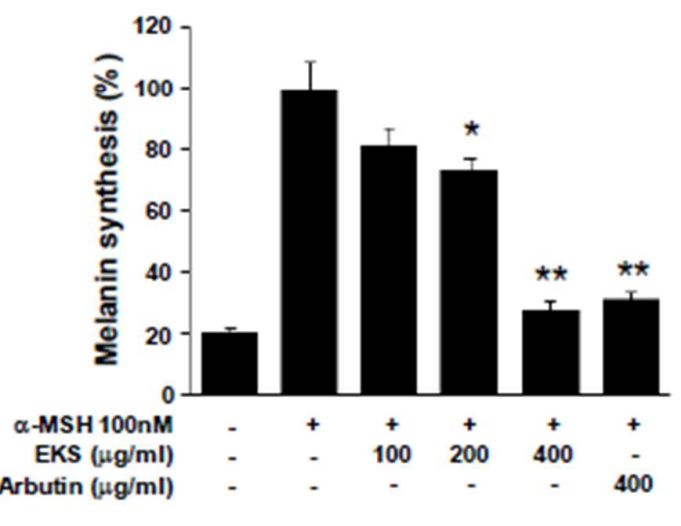

Figure 1. Effects of ethanolic extract of Kummerowia striata (EKS) on tyrosinase activity, cell viability, and melanin synthesis. (a) The tyrosinase inhibitory activity was analyzed by measuring the amount of dopachrome generated in the tyrosinase reaction. Arbutin was used as a positive control; (b) B16F10 mouse melanoma cells were treated with EKS $(25-400 \mu \mathrm{g} / \mathrm{mL})$. Cytotoxicity of EKS was determined by MTT assay; (c) Melanin content in B16F10 cells stimulated with $\alpha$-Melanocyte-stimulating hormone ( $\alpha$-MSH; $100 \mathrm{nM})$ and melanin synthesis were calculated as a percentage of values in the control. Values represent the means \pm SD of three independent replicates. Statistical significance is indicated $\left({ }^{*} \mathrm{P}<0.05,{ }^{* *} \mathrm{P}<0.01\right.$, compared to the nontreated or $\alpha$-MSH-treated cells).

\subsection{Anti-oxidant Activity of EKS}

To determine the antioxidant activityof EKS, two classic assays, namely the scavenging activity and scavenging capacity, were performed. The scavenging activity of EKS was determined using 2,2-diphenyl-1-picrylhydrazyl (DPPH) free radicals (Figure 2A). The results demonstrate that EKS exhibits higher antioxidant activity (Scavenging activity $=50.22 \%, \mathrm{IC}_{50}=98.71 \mu \mathrm{g} / \mathrm{mL}$ ). The scavenging capacity of EKS was also assessed using the 2,2'-azino-bis (3-ethylbenzothiazoline-6sulfonic acid) diammonium salt (ABTS) radical cation (Figure 2B). The ABTS radical scavenging capacity of EKS was similar to that of butylated hydroxyanisole (BHA), which was used as a positive control (Scavenging capacity $=99.53 \%, \mathrm{IC}_{50}=24.64 \mu \mathrm{g} / \mathrm{mL}$ ). These results indicate that EKS posses a high antioxidant activity. 
A

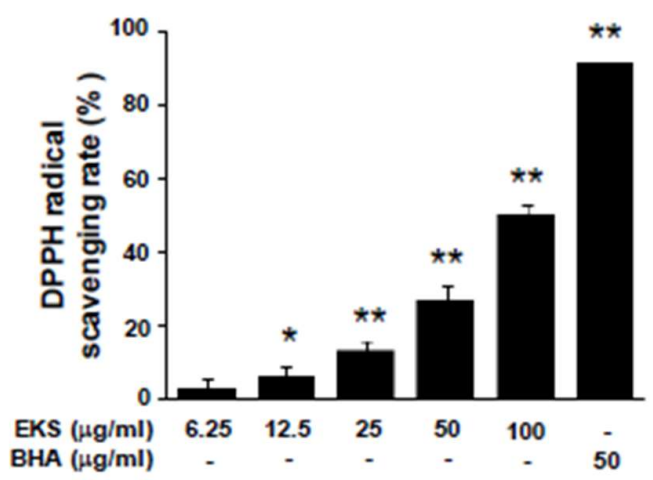

\begin{tabular}{cc}
\hline Sample & $\mid C_{50}(\mu g / \mathrm{ml})$ \\
\hline EKS & 98.71 \\
\hline BHA & 14.96 \\
\hline
\end{tabular}

B

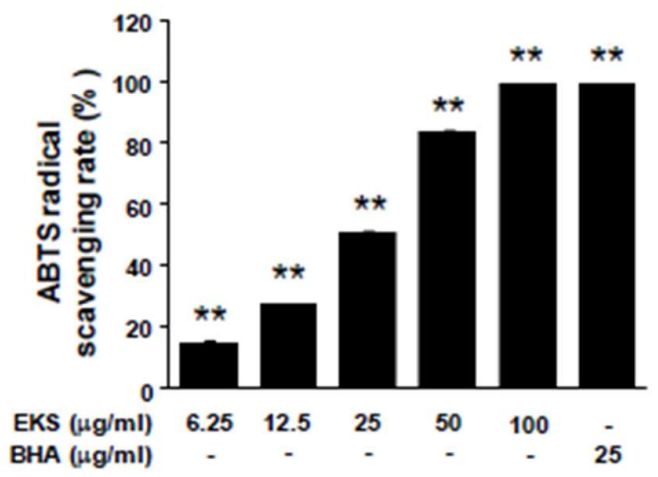

\begin{tabular}{cc}
\hline Sample & $\mathrm{IC}_{\mathrm{s}_{0}}(\mu \mathrm{g} / \mathrm{ml})$ \\
\hline EKS & 24.64 \\
\hline BHA & 4.65 \\
\hline
\end{tabular}

Figure 2. Effects of ethanolic extract of Kummerowia striata (EKS) on anti-oxidant activity. (a and b) Free radical scavenging activity was determined as described in materials and methods. Anti-oxidant activity was measured by using DPPH radical scavenging activity assay and $\mathrm{ABTS}^{+}$radical cation test. Butylated hydroxyanisole (BHA) was used as a positive control. Values represent the means \pm SD of three independent replicates. Statistical significance is indicated $\left({ }^{*} \mathrm{P}<0.05,{ }^{* *} \mathrm{P}<0.01\right.$, compared to the non-treated sample).

\subsection{Effect of EKS on the Expression of Genes Involved in Melanin Synthesis}

To further investigate the molecular mechanisms through which EKS regulates melanogenesis, we examined the changes in the expression of melanogenic genes and proteins, such as tyrosinase, tyrosinase-related protein 1 (TRP-1), tyrosinase-related protein 2 (TRP-2), and microphthalmia-associated transcription factor (MITF), which play pivotal roles in melanogenesis [13]. As shown in Figure 3A, the expression of these genes at the mRNA level was triggered by $\alpha$ $\mathrm{MSH}$, whereas EKS treatment caused a significant decrease in the expression (100-400 $\mu \mathrm{g} / \mathrm{mL})$. Moreover, EKS showed a similar potent inhibitory activity as did the positive control, arbutin. Next, the effect of the EKS on the expression of melanogenesis-related proteins was assessed by western blot analysis. The EKS treatment markedly inhibited the $\alpha$-MSH-induced expression levels of tyrosinase, TRP-1, TRP-2, and MITF in B16F10 cells (Figure 3B). Taken together, these findings demonstrate that the inhibitory effects of EKS on melanogenesis in B16F10 cells might be mediated through the down-regulation of melanogenic genes and proteins. 
A
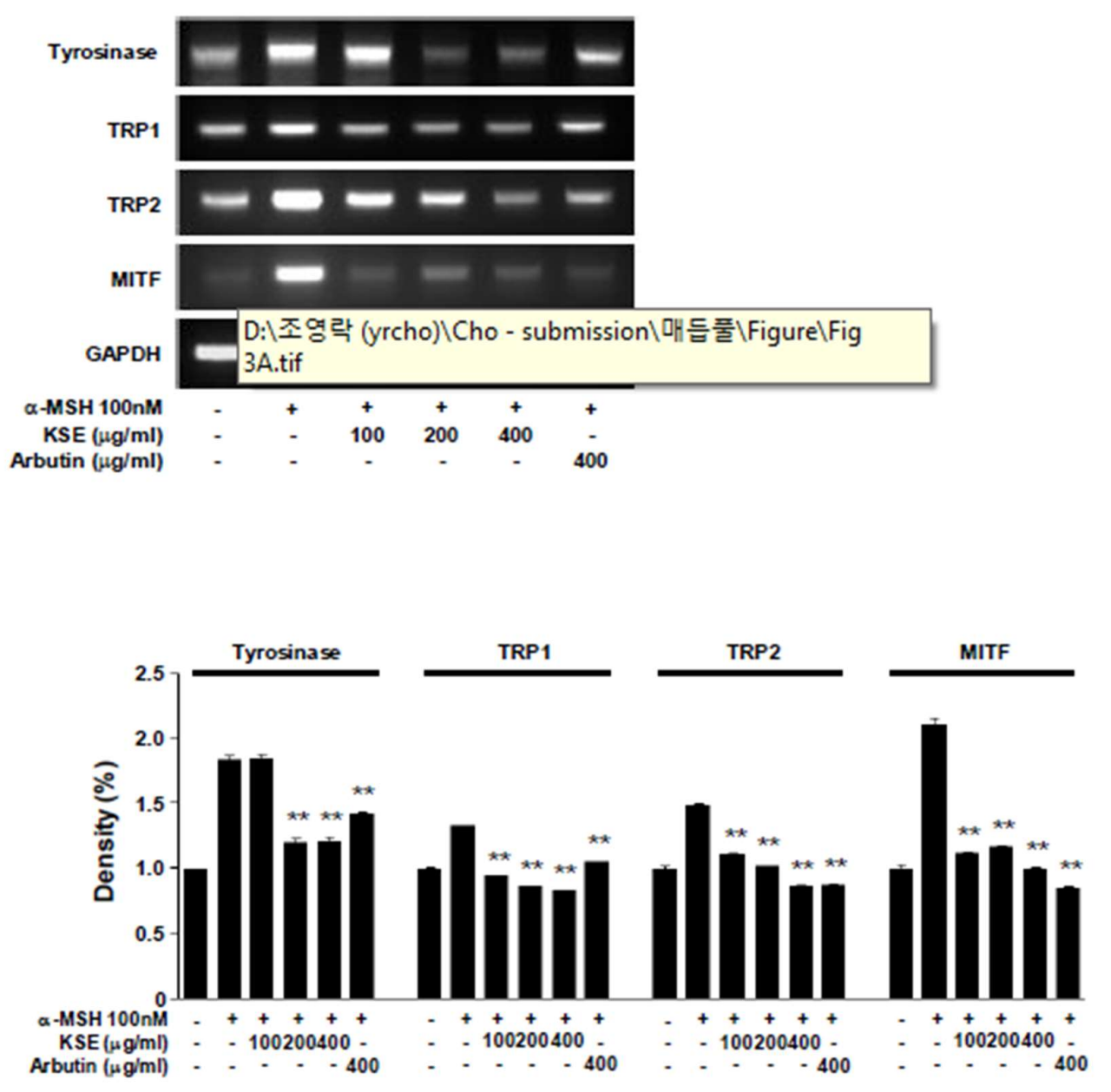
B
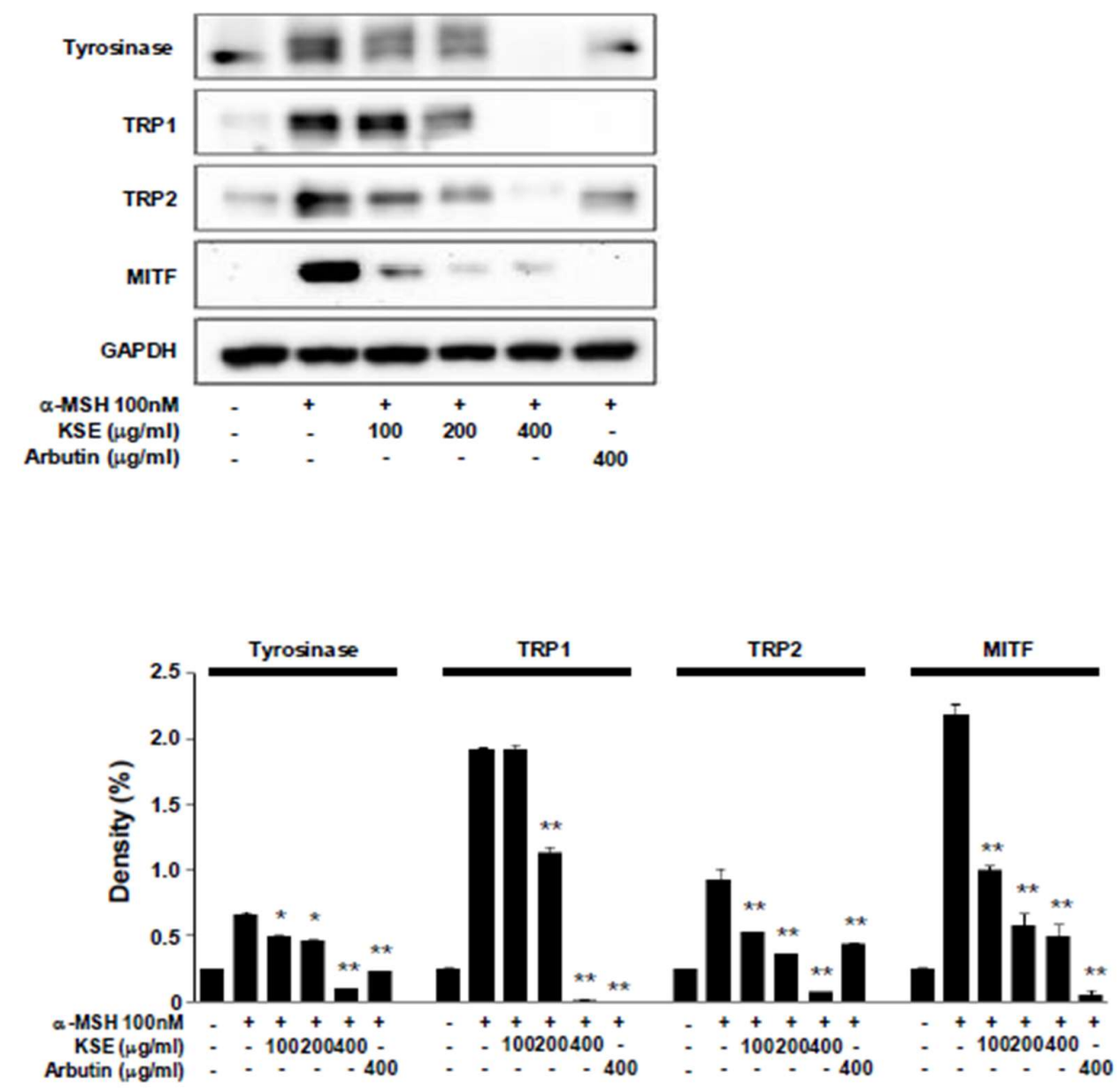

Figure 3. Effects of ethanolic extract of Kummerowia striata (EKS) on melanin biosynthesis. (a) The expression of tyrosinase, TRP1, TRP2, and MITF was determined at the mRNA level by RT-PCR followed by densitometry of the bands obtained. Arbutin was used as a positive control. (b) The expression of tyrosinase, TRP1, TRP2, and MITF was determined at the protein level by western blotting followed by densitometry of the bands obtained. Arbutin was used as a positive control. Values represent the means \pm SD of three independent replicates. Statistical significance is indicated $\left({ }^{*} \mathrm{P}<0.05,{ }^{*} \mathrm{P}<0.01\right.$, compared to the $\alpha$-MSHtreated cells).

2.4. p-coumaric Acid and Quercetin Present in EKS Exhibit Potent Anti-melanogenic and Anti-oxidant Activities

Next, we attempted to identify and purify the functional compounds present in EKS that exhibit potent anti-melanogenic and anti-oxidant activities. Various compounds, such as luteolin, palmitate, p-coumaric acid, rosmarinic acid, quercetin, genistein, and (+)-catechin, were identified. Among these, p-coumaric acid and quercetin showed tyrosinase inhibition and scavenging capacity in a dose-dependent manner, similar to arbutin, a well-known depigmenting agent (Figure 4). 
A

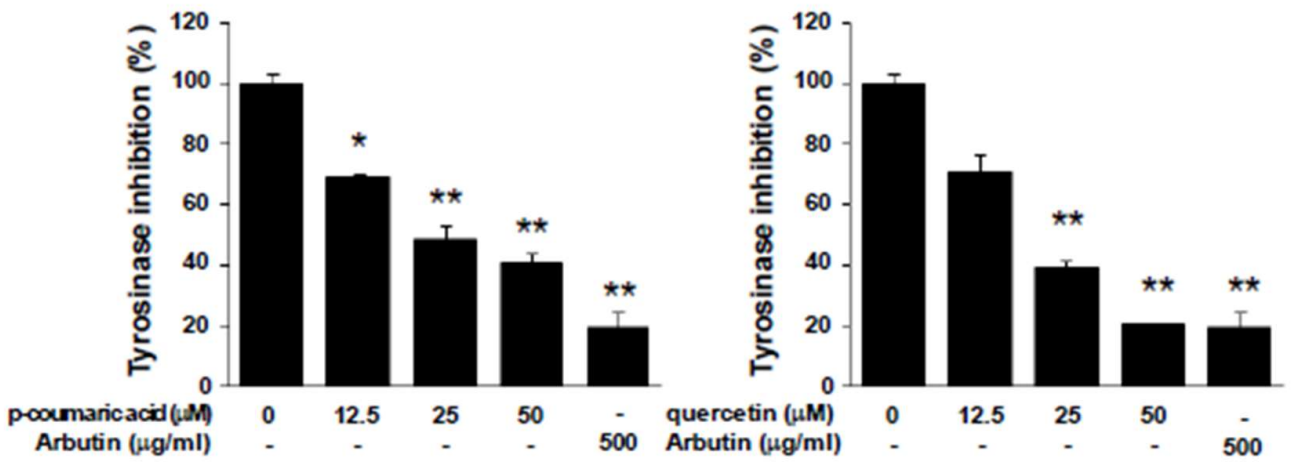

B
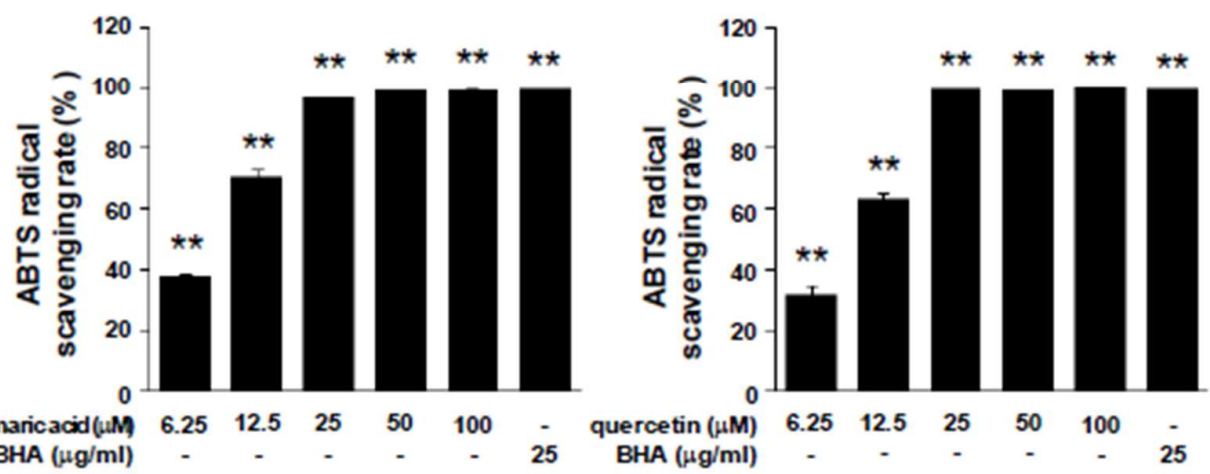

\begin{tabular}{cc}
\hline Sample & $I_{50}$ \\
\hline p-coumaric adid & $8.52 \mu \mathrm{M}$ \\
\hline quercetin & $10.45 \mu \mathrm{M}$ \\
\hline BHA & $4.65 \mu \mathrm{g} / \mathrm{ml}$ \\
\hline
\end{tabular}

Figure 4. Tyrosinase inhibition and anti-oxidant activities of selected compounds present in the ethanolic extract of Kummerowia striata (EKS). (a) The tyrosinase inhibitory activity of p-coumaric acid and quercetin $(12.5-50 \mu \mathrm{M})$ was analyzed. (b) Anti-oxidant activity of p-coumaric acid and quercetin $(6.25-100 \mu \mathrm{M})$ as assessed by $\mathrm{ABTS}^{+}$radical cation test. Arbutin was used as a positive control. Values represent the means $\pm \mathrm{SD}$ of three independent replicates. Statistical significance is indicated $\left({ }^{*} \mathrm{P}<0.05,{ }^{* *} \mathrm{P}<0.01\right.$, compared to the nontreated sample).

\section{Discussion}

Skin pigmentation is mostly caused by melanin cells in the basal layer of the skin, and is stimulated by UV radiation and anti-pigmentation compounds. The stimulated keratinocytes secrete $\alpha$-MSH, a small peptide hormone, (14). UV exposure induces melanin production resulting in hyperpigmentation [15]. Recently, many researchers have put much effort into identifying new and effective whitening compounds because cosmetics showing whitening effects have a large market. As a result of studies on inhibition of melanin biosynthesis, arbutin, kojic acid, and many 
other natural products were discovered to inhibit melanogenesis and hyperpigmentation. However, the side effects of arbutin [16] and kojic acid [17] have recently been reported, and the use of these chemical substances might be restricted. Therefore, there is a need to develop a whitening material having no side effect and is safe. Recently, several natural compounds have been investigated for use as whitening cosmetics.

Kummerowia striata is an unevenly distributed plant that has been used as a traditional herb for the treatment of inflammatory diseases. Several studies have demonstrated various biological activities of $K$. striata extracts. In particular, K. striata is pharmaceutically effective because of its anti-inflammatory and anti-oxidant activities [18,19]. However, the effects of $K$. striata on melanogenesis, and the underlying molecular mechanisms, have not been reported, as of date. In the present study, we demonstrate for the first time that the ethanol extract of $K$. striata possesses anti-melanogenic and anti-oxidant activities.

Tyrosinase, TRP-1, and TRP-2 play important roles in melanin biosynthesis [20]. Thus, mechanisms that influence the effect of skin whitening agents are assumed to inhibit melanin production by lowering the tyrosinase activity (21). The expression of tyrosinase, TRP-1, and TRP-2 genes is known to be regulated by MITF [22]. In the present study, the anti-melanogenic activity of EKS and inhibition of $\alpha$-MSH-induced melanin synthesis in B16F10 melanoma cells were found to be mediated by the inhibition of the tyrosinase activity and the EKS treatment did not cause any cytotoxicity (Figure 1). The anti-melanogenic activity of EKS was found to be mediated by the down-regulation of $\alpha$-MSH-induced expression of tyrosinase, TRP-1, TRP-2, and MITF at the mRNA and protein levels (Figure 3). The anti-oxidant activity of EKS was measured by DPPH and ABTS assays, which revealed that EKS possesses strong antioxidant activity similar to BHA (Figure 2). We subsequently identified the active compounds present in EKS and confirmed the presence of p-coumaric acid and quercetin. Although various biological activities, including cardioprotective [23], anti-inflammatory [24,25], anti-mutagenic [26], anti-oxidant [27,28], and anti-melanogenic [29] activities have been reported for p-coumaric acid and quercetin present in various plants, this is the first report on the presence and anti-melanogenic and anti-oxidant activities of these compounds in EKS.

\section{Materials and Methods}

\subsection{Cell Culture Conditions}

The murine B16F10 melanoma cell line was purchased from the American Type Culture Collection (Manassas, VA, USA). The cells were cultured in Dulbecco's Modified Eagle Medium (DMEM; Gibco, San Jose, CA, USA), supplemented with $10 \%$ fetal bovine serum and penicillin/stereptomycin (Gibco, USA) in a humidified atmosphere containing $5 \% \mathrm{CO}_{2}$ in air at $37^{\circ} \mathrm{C}$.

\subsection{Reagents}

The following antibodies were purchased from commercial sources: anti- tyrosinase, anti-TRP1, anti-TRP-2, and anti-MITF antibodies very purchased from ThermoFisher Scientific (Rockford, IL, USA) and mouse anti- $\beta$-actin antibody and rabbit IgG-horseradish peroxidase conjugated antibody were purchased from Cell Signaling (Beverly, MA, USA).

\subsection{Preparation of K. striata Extract}

The aerial parts of Kummerowia striata (Thunb. ex Murray) Schindler were collected at Gimpo, Gyeonggi, South Korea in September 2013 and identified by Professor Joa Sub Oh, College 
of Pharmacy, Dankook University, Cheonan, South Korea. A voucher specimen (G63) has been deposited at the Bio-center, Gyeonggido Business \& Science Accelerator, Suwon, South Korea. The aerial parts of K. striata (Thunb. ex Murray) Schindler $(1.8 \mathrm{Kg})$ were extracted with $70 \% \mathrm{EtOH}(3 \times$ $18 \mathrm{~L}$ ) at room temperature. The combined $\mathrm{EtOH}$ extracts were then concentrated in vacuo at $40^{\circ} \mathrm{C}$ to yield $180 \mathrm{~g}$ of residue. The $\mathrm{EtOH}$ extract was suspended in distilled water and then partitioned, in turn, with $\mathrm{CH} 2 \mathrm{Cl} 2$, EtOAc and $\mathrm{n}-\mathrm{BuOH}$. The fraction of $\mathrm{MC}(7.52 \mathrm{~g})$, was separated by liquid column chromatography [glass column $(7.5 \times 40 \mathrm{~cm})$ packed with Silica gel $(70-230$ mesh)] that used gradient mixtures as eluents $(\mathrm{CH} 2 \mathrm{Cl} 2 \rightarrow \mathrm{MeOH})$. The eluent fractions F001 F006 were obtained from this initial liquid chromatographic separation. Fraction F003 was purified by column chromatography using a glass column $(5.0 \times 40 \mathrm{~cm})$ packed with ODS-C18 gel. The column was then eluted with ( $\mathrm{H} 2 \mathrm{O} \rightarrow \mathrm{MeOH}$ ) resulting in seven subfractions (F007-F013). p-Coumaric acid $(15.2 \mathrm{mg})$ was isolated from F007 that used by liquid column chromatography [glass column $(3.0 \times$ $40 \mathrm{~cm})$ packed with ODS-C18] using gradient elution $(\mathrm{H} 2 \mathrm{O} \rightarrow \mathrm{MeOH})$. Quercetin $(13.5 \mathrm{mg})$ was isolated from F004 that used by liquid column chromatography [glass column $(3.0 \times 40 \mathrm{~cm})$ packed with ODS-C18] using gradient elution $(\mathrm{H} 2 \mathrm{O} \rightarrow \mathrm{MeOH})$. Their structures were elucidated by a combination of 1D and 2D NMR, and MS spectrometry as well as comparison with reported literatures [30,31].

\subsection{General procedures}

1D and 2D (1H-1H COSY, HSQC, and HMBC) NMR spectra were measured on a Bruker Ascend III $700 \mathrm{MHz}$ NMR spectrometer (Rheinstetten, Germany) with tetramethylsilane as an internal standard, and chemical shifts are expressed in $\delta$ values. Electrospray ionization (ESI) mass spectra were obtained on a LTQ Orbitrap XL (Thermo Scientific) mass spectrometer. Open column chromatography was performed using silica gel (Kiesel gel 60, 70-230 mesh and 230-400 mesh; Merck), ODS-C18 gel ODS-A (12 nm S-7 $\mu \mathrm{m}$, YMC GEL, Japan). Thin layer chromatography using pre-coated silica gel 60 F254 $(0.25 \mathrm{~mm}$, Merck) and pre-coated silica gel 60 RP-18 F-254S $(0.25 \mathrm{~mm}$, Merck), respectively. All chemicals and solvents were of analytical grade and used without further purification.

\subsection{Cell Viability Assay}

The 3-(4dimethylthiazol-2-yl)-2,5-diphenyl-tetrazolium bromide (MTT) assay was performed to determine the effect of the extract on cell viability. B16F10 mouse melanoma cells were cultured in 96-well plates $\left(1 \times 10^{4}\right.$ cells/well $)$ and were treated with EKS for $24 \mathrm{~h}$. Serum-free medium $(100 \mu \mathrm{L})$ containing $10 \%$ MTT solution $(5 \mathrm{mg} / \mathrm{mL})$ was added and the plates were incubated for $3 \mathrm{~h}$. The medium was removed and the cells were washed twice with phosphate buffered saline (PBS). Thereafter, an extract was prepared by dissolution in $100 \mu \mathrm{L}$ of dimethyl sulfoxide (DMSO) on a shaker, and absorbance was read at $540 \mathrm{~nm}$ using an ELISA plate reader (Molecular Device, USA).

\subsection{Determination of Melanin Content in Cells}

The B16F10 cells were cultured in 6-well plates at a density of $1 \times 10^{5}$ cells per well and incubated for $24 \mathrm{~h}$. Melanogenesis was induced with $100 \mathrm{nM} \alpha-\mathrm{MSH}$, and the cells were treated with different concentrations of arbutin (a positive control) and EKS and further cultured for $72 \mathrm{~h}$. After washing with PBS twice, the cells were lysed in the lysis buffer $(100 \mathrm{mM}$ sodium phosphate ( $\mathrm{pH}$ 6.8), $0.1 \mathrm{mM} \mathrm{PMSF}, 1 \%$ Triton $\mathrm{X}-100$ ) by incubating at $-80^{\circ} \mathrm{C}$ for $30 \mathrm{~min}$. The cell pellet was dissolved in $1 \mathrm{~N} \mathrm{NaOH}$ containing $10 \%$ DMSO at $65{ }^{\circ} \mathrm{C}$ for $1 \mathrm{~h}$, and the absorbance was read at 405 nm.

\subsection{Tyrosinase Inhibition Assay}

The tyrosinase inhibition assay was performed by the method of Yagi et al. [32]. The reaction was carried out in $0.1 \mathrm{M}$ potassium phosphate buffer ( $\mathrm{pH} 6.5$ ) containing $1.5 \mathrm{mM} \mathrm{L-}$ tyrosine and $1250 \mathrm{unit} / \mathrm{mL}$ mushroom tyrosinase by incubating at $37^{\circ} \mathrm{C}$ for $20 \mathrm{~min}$. The test samples 
were assayed for tyrosinase inhibition by measuring their effect on the tyrosinase activity using an ELISA plate reader at $490 \mathrm{~nm}$. Arbutin was used as a positive control.

\subsection{DPPH Radical Scavenging Activity Assay}

The DPPH radical scavenging activity was measured by the method of Blois [33] and Ozgen et al. [34], which is a simple method for measuring the activity of antioxidants in a sample. DPPH solution $(100 \mu \mathrm{L})$ in methanol was added to $100 \mu \mathrm{L}$ of EKS, which used at different concentrations, and the reaction was carried out at room temperature for $30 \mathrm{~min}$. The absorbance was measured at $517 \mathrm{~nm}$ using an ELISA plate reader and the $\mathrm{IC}_{50}$ value was determined (Molecular Device, USA). The antioxidant, BHA, was used as a positive control.

\subsection{ABTS Radical Scavenging Activity}

The ABTS radical scavenging activity was determined by the method of Miller et al. [35] and Dudonne et al. [36]. ABTS ${ }^{+}$was formed by mixing $7 \mathrm{mM}$ ABTS solution and $2.45 \mathrm{mM}$ potassium persulfate $\left(\mathrm{K}_{2} \mathrm{~S}_{2} \mathrm{O}_{8}\right)$ solution (ABTS: $\mathrm{K}_{2} \mathrm{~S}_{2} \mathrm{O}_{8}=2: 1$ ) for $12-16 \mathrm{~h}$ to form a cation (ABTS $)$; the absorbance of the solution at $734 \mathrm{~nm}$ was $1.35 \pm 0.05$. The diluted solution $(100 \mu \mathrm{L})$ and different concentrations of EKS $(100 \mu \mathrm{L})$ were reacted at room temperature for $6 \mathrm{~min}$ and the absorbance was measured at $734 \mathrm{~nm}$ using an ELISA reader. BHA was used as a positive control. The IC 50 value of EKS was determined using the values obtained.

\subsection{Reverse Transcription-Polymerase Chain Reaction (RT-PCR)}

The B16F10 melanoma cells were seeded in 6-well plates at a density of $1 \times 10^{6}$ cells/well and treated with EKS (100-400 $\mu \mathrm{g} / \mathrm{mL})$ for $72 \mathrm{~h}$. To extract total RNA, Trizol reagent (Invitrogen, Thermo Fisher Scientific, Inc.) was added to each well to lyse the cells and $200 \mu \mathrm{L}$ of chloroform was added. Thereafter, the mixture was centrifuged at $13,000 \mathrm{rpm}$ for $20 \mathrm{~min}$ at $4{ }^{\circ} \mathrm{C}$, and the supernatant was mixed with isopropanol for $30 \mathrm{~min}$ at $-70{ }^{\circ} \mathrm{C}$. After centrifugation at $13,000 \mathrm{rpm}$ for $20 \mathrm{~min}$ at $4{ }^{\circ} \mathrm{C}$, the supernatant was removed, and $70 \% \mathrm{EtOH}$-diethylpyrocarbonate treated water was added to each tube. After centrifugation at $13,000 \mathrm{rpm}$ for $5 \mathrm{~min}$ at $4{ }^{\circ} \mathrm{C}$, the supernatant was removed and dried at room temperature. The extracted total RNA $(1 \mu \mathrm{g})$ was reverse transcribed to single stranded cDNA with oligo dT primers using Taq DNA polymerase and SuperScript ${ }^{\circledR} I I I$ FirstStrand Synthesis System (Invitrogen, Thermo Fisher Scientific, Inc.). The cDNA was amplified on

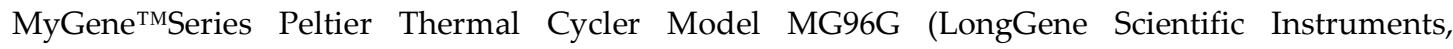
Hangzhou, China) using specific primers and AccuPower® Pfu PCR premix (Bioneer Corporation, Daejeon, Republic of Korea). The PCR cycling conditions were $5 \mathrm{~min}$ at $95^{\circ} \mathrm{C}$, followed by 30 cycles of $30 \mathrm{sec}$ at $95{ }^{\circ} \mathrm{C}, 30 \mathrm{sec}$ at $60{ }^{\circ} \mathrm{C}, 1 \mathrm{~min}$ at $72{ }^{\circ} \mathrm{C}$, and final extension for $10 \mathrm{~min}$ at $72{ }^{\circ} \mathrm{C}$. After amplification, the PCR products were electrophoresed on $1.5 \%$ agarose gel containing ethidium bromide and analyzed using a UV transilluminator.

\subsection{Western Blot Analysis}

The B16F10 melanoma cells were cultured in DMEM supplemented with $10 \%$ FBS at a density of $1 \times 10^{6}$ cells in 6-well plates at $37^{\circ} \mathrm{C}$ and $5 \% \mathrm{CO}_{2}$ for $24 \mathrm{~h}$. After removing the culture medium, EKS (100-400 $\mu \mathrm{g} / \mathrm{mL})$ diluted in the medium was treated for $72 \mathrm{~h}$. The cells were washed with PBS and harvested using RIPA buffer (Sigma Aldrich), and subsequently centrifuged at 15,000 $\mathrm{rpm}$ for $15 \mathrm{~min}$ at $4{ }^{\circ} \mathrm{C}$. The total protein was extracted from cells and quantified by Bradford method. The proteins were separated by $8 \%$ sodium dodecyl sulfate polyacrylamide gel electrophoresis (SDS-PAGE) and transferred onto nitrocellulose membrane (Whatman, Dassel, Germany). The membrane was blocked with 5\% BSA for $1 \mathrm{~h}$ at room temperature and incubated overnight with primary antibody at $4^{\circ} \mathrm{C}$. The membrane was subsequently washed and incubated with Horesradish peroxidase (HRP)-conjugated secondary antibody for $1 \mathrm{~h}$ at room temperature. The membrane was washed again and the proteins were detected using SuperSignal® West Pico Chemiluminescent Substrate (ThermoFisher Scientific, Rockford, IL, USA). 
Statistical analysis was performed by Student's $t$-test using Microsoft Excel 2007 (Microsoft Corporation, Redmond, WA, USA). The results are presented as the means \pm standard deviation, and $P<0.05$ was considered to indicate a statistically significant difference.

\title{
5. Conclusions
}

In the present study, we evaluated the anti-melanogenic and anti-oxidant activities of the ethanolic extract of K. striata. EKS exhibited potent anti-melanogenic and anti-oxidant activities by regulating the tyrosinase activity and inhibited $\alpha$-MSH-induced melanin synthesis in B16F10 melanoma cells without inducing cytotoxicity. We attribute these activities mainly to the presence of the active compounds, p-coumaric acid and quercetin. Our findings demonstrate, for the first time, that EKS may be utilized as a potential depigmenting and anti-oxidant agent.

Acknowledgments: This work was supported by the Technology development Program (S2393982) funded by the Ministry of SMEs and Startups (MSS, Korea).

Author Contributions: All authors contributed equally to this work.

Conflicts of Interest: The authors declare that they have no competing interests.

\author{
Abbreviations \\ ABTS 2,2'-azino-bis (3-ethylbenzothiazoline-6-sulfonic acid) diammonium salt \\ BHA butylated hydroxyanisole \\ DPPH 2,2-diphenyl-1-picrylhydrazyl \\ EKS ethanol extract of kummerowia striata \\ k. striata Kummerowia striata \\ TRP-1 tyrosinase-related protein 1 \\ TRP-2 tyrosinase-related protein 2 \\ MITF microphthalmia-associated transcription factor \\ $\alpha$-MSH $\quad \alpha$-Melanocyte-stimulating hormone
}

\section{References}

1. Limtrakul, P.; Yodkeeree, S.; Thippraphan, P., Punfa, W., Srisomboon, J. Anti-aging and tyrosinase inhibition effects of Cassia fistula flower butanolic extract. BMC Complement. Altern. Med. 2016, 16, 497.

2. Gragnani, A.; Cornick, S.; Chominski, V; Ribeiro de Noronha, S.; Alves Corrêa de Noronha, S.; Ferreira, L. Review of major theories of skin aging. Adv. Aging Res. 2014, 3, 265-284.

3. Pedrosa, T.D.; Barros, A.O.; Nogueira, J.R.; Fruet, A.C.; Rodrigues, I.C.; Calcagno, D.Q.; Smith, M.A.; de Souza, T.P.; et al. Anti-wrinkle and anti-whitening effects of jucá (Libidibia ferrea Mart.) extracts. Arch Dermatol. Res. 2016, 308, 643-654.

4. Delalle-Lozica, N. Local therapy as basic anti-aging prevention. Acta Clin. Croat. 2010, 49, 529-536.

5. Maddodi, N.; Jayanthy, A.; Setaluri, V. Shining light on skin pigmentation: the darker and the brighter side of effects of UV radiation. Photochem. Photobiol. 2012, 88, 1075-1082.

6. Dessinioti, C.; Stratigos, A.J.; Rigopoulos, D.; Katsambas, A.D. A review of genetic disorders of hypopigmentation: lessons learned from the biology of melanocytes. Exp. Dermatol. 2009, 18, 741-749.

7. Nishina, A.; Miura, A.; Goto, M.; Terakado, K.; Sato, D.; Kimura, H.; Hirai, Y.; Sato, H. Phay, N. Mansonone E from Mansonia gagei inhibited $\alpha$-MSH-induced melanogenesis in B16 cells by inhibiting CREB expression and phosphorylation in the PI3K/Akt pathway. Biol. Pharm. Bull. 2018, 41, 770-776.

8. Hearing, V.J.; Ekel, T.M. Mammalian tyrosinase. A comparison of tyrosine hydroxylation and melanin formation. Biochem. J. 1976, 57, 549-557.

9. Kanlayavattanakul, M.; Lourith, N. Plants and natural products for the treatment of skin hyperpigmentation-A Review. Planta Med. 2018. DOI: 10.1055/a-0583-0410.

10. Kanlayavattanakul, M.; Lourith, N. Skin hyperpigmentation treatment using herbs: A review of clinical evidences. J. Cosmet. Laser Ther. 2018, 20, 123-131.

11. Hsiao, J.J.; Fisher, D.E. The roles of microphthalmia-associated transcription factor and pigmentation in melanoma. Arch. Biochem. Biophys. 2014, 563, 28-34. 
12. Garraway, L.A.; Widlund, H.R.; Rubin, M.A.; Getz, G.; Berger, A.J.; Ramaswamy, S.; Beroukhim, R.; Milner, D.A.; Granter, S.R.; et al. Integrative genomic analyses identify MITF as a lineage survival oncogene amplified in malignant melanoma. Nature. 2005, 436, 117-122.

13. Otreba, M.; Rok, J.; Buszman, E.; Wrzesniok, D. Regulation of melanogenesis: the role of cAMP and MITF. Postepy Hig. Med. Dosw. 2012, 66, 33-40.

14. Han, J.S.; Sung, J.H.; Lee, S.K. Antimelanogenesis activity of hydrolyzed ginseng extract (GINST) via inhibition of JNK mitogen-activated protein kinase in B16F10 cells. J. Food Sci. 2016, 81, H2085-2092.

15. Chatatikun, M.; Chiabchalard, A. Thai plants with high antioxidant levels, free radical scavenging activity, anti-tyrosinase and anti-collagenase activity. BMC Complement. Altern. Med. 2017, 17, 487.

16. Couteau, C.; Coiffard, L.J. Photostability determination of arbutin, a vegetable whitening agent. Farmaco. 2000, 55, 410-413.

17. Higashi, Y.; Fujii, Y. Determination of kojic acid in a skin-whitening cosmetic by high-performance liquid chromatography coupled with ultraviolet detection after pre-column derivatization with 4-fluoro-7-nitro2,1,3-benzoxadiazole. J. Cosmet. Sci. 2017, 63, 205-212.

18. Tao, J.Y.; Zhou, L.; Huang, Z.J.; et al. Anti-inflammatory effects of ethanol extract from Kummerowia striata (Thunb.) Schindl on LPS-stimulated RAW264.7 cell. Inflammation. 2008, 31, 154-166.

19. Lee, J.H.; Park, J.S. Antioxidant activities of solvent-extracted fractions from Kummerowia striata (Thunb.) Schindl. Indian J. Sci. Technol. 2015, 8, 28-31.

20. Kippenberger, S.; Loitsch, S.; Solano, F.; Bernd, A.; Kaufmann, R. Quantification of tyrosinase, TRP-1, and Trp-2 transcripts in human melanocytes by reverse transcriptase-competitive multiplex PCR-regulation by steroid hormones. J. Invest. Dermatol. 1998, 110, 364-367.

21. Park, Y.D.; Kim, S.Y.; Lyou, Y.J.; Lee, D.Y.; Yang, J.M. TXM13 human melanoma cells: a novel source for the inhibition kinetics of human tyrosinase and for screening whitening agents. Biochem. Cell Biol. 2006, $84,112-116$.

22. Tuerxuntayi, A.; Liu, Y.Q.; Tulake, A.; Kabas, M.; Eblimit, A.; Aisa, H.A. Kaliziri extract upregulates tyrosinase, TRP-1, TRP-2 and MITF expression in murine B16 melanoma cells. BMC Complement. Altern. Med. 2014, 14, 166.

23. Prasanna, N.; Krishnan, D.N.; Rasool, M. Sodium arsenite-induced cardiotoxicity in rats: protective role of p-coumaric acid, a commo dietary polyphenol. Toxicol. Mech. Methods. 2013, 23, 255-262.

24. Pragasam, S.J.; Venkatesan, V.; Rasool, M. Immunomodulatory and anti-inflammatory effect of pcoumaric acid, a common dietary polyphenol on experimental inflammation in rats. Inflammation. 2013, 36, 169-176.

25. Lee, M.; Son, M.; Ryu, E.; Yu, S.S.; Kim, J.G.; Kang, B.W.; Sung, G.H.; Cho, H.; Kang, H. Quercetininduced apoptosis prevents EBV infection. Oncotarget. 2015, 6, 12603-12624.

26. Ferguson, L.R.; Lim, I.F.; Pearson, A.E.; Ralph, J.; Harris, P.J. Bacterial antimutagenesis by hydroxycinnamic acids from plant cell walls. Mutat. Res. 2003, 542, 49-58.

27. Castelluccio, C.; Paganga, G.; Melikian, N. et al. Antioxidant potential of intermediates in phenylpropanoid metabolism in higher plants. FEBS Lett. 1995, 368, 188-192.

28. Erden, I.M.; Kahraman, A. The protective effect of flavonol quercetin against ultraviolet a induced oxidative stress in rats. Toxicology. 2000, 154, 21-29.

29. An, S.M.; Koh, J.S.; Boo, Y.C. p-coumaric acid not only inhibits human tyrosinase activity in vitro but also melanogenesis in cells exposed to UVB. Phytother. Res. 2010, 24, 1175-1180.

30. Zhang, X.; Guo, P.; Sun, G. et al. Phenolic compounds and flavonoids from the fruits of Pandanus tectorius Soland. J. Med. Plants Res. 2012, 6, 2622-2626.

31. Li, H.; Ma, Q.; Liu, Y.; Qian, J.; Zhou, J.; Zhou, Y. Chemical constituents from Polygonum perfoliatum. Chin. J. Appl. Environ. Biol. 2009, 15, 615-620.

32. Yagi A, Kanbara T, Morinobu N. Inhibition of mushroom-tyrosinase by aloe extract. Planta Med. 1987, 56, 515-517.

33. Blois, M.S. Antioxidant determinations by the use of a stable free radical. Nature. 1958, 181, 1199-1200.

34. Ozgen, U.; Mavi, A.; Terzi, A.; Yıldırım, A.; Coşkun, M.; Houghton, P.J. Antioxidant properties of some medicinal Lamiaceae species. Pharm. Biol. 2006, 44, 107-112.

35. Milner et al. A novel method for measuring antioxidant capacity and its application to monitoring the antioxidant status in premature neonates. Clin. Sci. 1993, 84, 407-412. 


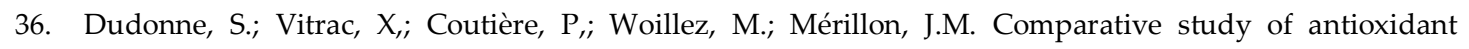
properties and total phenolic content of 30 plant extracts of industrial interest using DPPH, ABTS, FRAP, SOD, and ORAC assays. J. Agric. Food Chem. 2009, 57, 1768-1774. 